\title{
Hypertension as a Risk Factor for Contrast-Associated Acute Kidney Injury: A Meta-Analysis Including 2,830,338 Patients
}

\author{
Zhubin Lun a, b, Ziling Mai $^{d} \quad$ Liwei Liu $^{a, e}$ Guanzhong Chen ${ }^{a}$ d Huanqiang Li ${ }^{a}$ \\ Ming Ying ${ }^{a}$ Bo Wang ${ }^{a}$ Shiqun Chen ${ }^{a}$ Yongquan Yang ${ }^{a}$ Jin Liu ${ }^{a}$ \\ Jiyan Chen ${ }^{a, e, f}$ Jianfeng Ye $e^{b, c}$ Yong Liüa, e,

\begin{abstract}
aDepartment of Cardiology, Guangdong Provincial Key Laboratory of Coronary Heart Disease Prevention, Guangdong Cardiovascular Institute, Guangdong Provincial People's Hospital, Guangdong Academy of

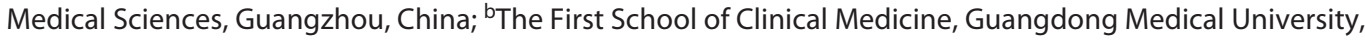
Zhanjiang, China; 'Department of Cardiology, Dongguan TCM Hospital, Dongguan, China; ${ }^{\mathrm{d}}$ Guangdong Provincial People's Hospital, School of Biology and Biological Engineering, South China University of Technology, Guangzhou, China; ${ }^{\mathrm{e} T}$ The Second School of Clinical Medicine, Southern Medical University, Guangzhou, China; fGuangdong Provincial People's Hospital, School of Medicine, South China University of Technology, Guangzhou, China
\end{abstract}

\section{Keywords}

Hypertension · Contrast-associated acute kidney injury ·

Meta-analysis · Adjusted odds ratio

\begin{abstract}
Objective: Previous studies have shown that the relationship between hypertension ( $\mathrm{HT}$ ) and contrast-associated acute kidney injury (CA-AKI) is not clear. We apply a systematic review and meta-analysis to assess the association between HT and CA-AKI. Methods: We searched for articles on the study of risk factors for CA-AKI in the Embase, Medline, and Cochrane Database of Systematic Reviews (by March 25, 2021). Two authors independently performed quality assessment and extracted data such as the studies' clinical setting, the definition of CA-AKI, and the number of patients. The CA-AKI was defined as a serum creatinine ( $\mathrm{SCr}$ ) increase $\geq 25 \%$ or $\geq 0.5$ $\mathrm{mg} / \mathrm{dL}$ from baseline within $72 \mathrm{~h}$. We used fixed or random
\end{abstract}

karger@karger.com www.karger.com/kbr

Karger $\stackrel{\text { ' }}{=}$

BOPEN ACCESS
(C) 2021 The Author(s)

Published by S. Karger AG, Basel

This is an Open Access article licensed under the Creative Commons Attribution-NonCommercial-4.0 International License (CC BY-NC) (http://www.karger.com/Services/OpenAccessLicense), applicable to the online version of the article only. Usage and distribution for commercial purposes requires written permission. models to pool adjusted OR (aOR) by STATA. Results: A total of 45 studies $(2,830,338$ patients) were identified, and the average incidence of CA-AKI was $6.48 \%$. There was an increased risk of CA-AKI associated with HT (aOR: 1.378, 95\% Cl: 1.211$\left.1.567, I^{2}=67.9 \%\right)$. In CA-AKI with a SCr increase $\geq 50 \%$ or $\geq 0.3$ $\mathrm{mg} / \mathrm{dL}$ from baseline within $72 \mathrm{~h}$, an increased risk of CA-AKI was associated with $\mathrm{HT}$ (aOR: 1.414, 95\% Cl: 1.152-1.736, $I^{2}=$ $0 \%$ ). In CA-AKI with a Scr increase $\geq 50 \%$ or $\geq 0.3 \mathrm{mg} / \mathrm{dL}$ from baseline within 7 days, $\mathrm{HT}$ increases the risk of CA-AKI (aOR: 1.317, 95\% Cl: $\left.1.049-1.654, I^{2}=51.5 \%\right)$. Conclusion: Our meta-analysis confirmed that $\mathrm{HT}$ is an independent risk factor for CA-AKI and can be used to identify risk stratification. Physicians should pay more attention toward prevention and treatment of patients with $\mathrm{HT}$ in clinical practice.

(c) 2021 The Author(s)

Published by S. Karger AG, Basel

\section{Z.L., Z.M., L.L., and G.C. contributed equally to this work.}

Correspondence to:

Jianfeng Ye,yipjf@ hotmail.com

Yong Liu, liuyong@gdph.org.cn 


\section{Introduction}

As a common complication after coronary angiography, contrast-associated acute kidney injury (CA-AKI) had become one of the three major in-hospital AKI, and it would bring adverse prognosis [1-5]. Therefore, early prevention of CA-AKI is very necessary. Hypertension (HT) was used as a powerful predictor in high-performance predictive models, and it had been confirmed in previous studies that HT can increase the risk of CA-AKI [6-9]. However, in an article exploring the relationship between left ventricular ejection fraction and CA-AKI in patients with heart failure, it was found that the association between HT and CA-AKI was not significant [10]. At the same time, Sun, Barbieri, and Chong et al. [11-13] observed that HT was not an independent risk factor for CA-AKI.

Hence, the relationship between HT and CA-AKI was still controversial. For the first time, we systematically evaluated the relationship between HT and CA-AKI through this meta-analysis.

\section{Methods}

\section{Search Strategy}

We mainly conducted a search on the Ovid Medline, Embase, and Cochrane system review databases, limited to English language articles published up to March 25, 2021. Search terms were related to "risk factor," "contrast," and "acute kidney injury." When we found other keywords during an electronic search, we modified the search strategy to upgrade the terms and record them (details in online suppl. Items 13; for all online suppl. material, see www.karger.com/doi/10.1159/000517560). The flowchart of the study selection is detailed in Figure 1 (PROSPERO register number: CRD42019121534). The study is reported according to the Meta-analysis of Observational Studies in Epidemiology (MOOSE) reporting guideline [14].

\section{Selection Criteria}

Two authors (Z.B.L. and Z.L.M.) independently screened the articles by reading the title and abstract, and then the full texts of studies found potentially eligible were obtained and further assessed for final inclusion. When encountering a dispute, the decision is made by a third assessor (Y.L. and J.F.Y.). We considered the observational studies that reported the odds ratio between CA$\mathrm{AKI}$ and $\mathrm{HT}$ in the multivariate analysis. The longitudinal studies about CA-AKI incidence that include the risk factor of CA-AKI are also selected. If multiple studies are from the same cohort or most of the population is repeated, then we will choose the article that contains most of the people. We excluded animal studies, randomized control trials, case reports, review, meta-analysis, letter, notes, guidelines, non-English kinds of literature, and not risk factors for CA-AKI that only included prevalence. All writers are well-trained to perform systematic reviews and meta-analysis.

A Meta-Analysis of Contrast-Associated Acute Kidney Injury and Hypertension
Quality Assessment

Those included study quality assessment was based on the Newcastle-Ottawa Scale (NOS), performed by 2 independent authors (Z.B.L. and M.Z.L.), and the debate was resolved by a third researcher (J.F.Y.). The Newcastle-Ottawa Scale determines the quality of an article by rating the article's participant selection, compatibility, and outcomes/exposures. The score used for the NOS defined "low-quality studies" as those with scores of 1-3, "moderate-quality studies" as those with scores of 4-6 and "highquality studies" as 7-9.

\section{Data Extraction from the Selected Articles}

Two authors (Z.B.L. and M.Z.L.) analyzed each article and extracted detailed information of each article: country, region, year, study characteristics, patient population, the number of CA-AKI, adjustment rate and adjusted odds ratio (aOR). Cross-check was performed to ensure the data are correct. Disagreements were settled by discussion between the reviewers and judges. In our analysis, there are 3 definitions of CA-AKI. (1) CA-AKI ${ }^{\mathrm{A}}$ was defined as an absolute increase in $\mathrm{SCr} \geq 0.5 \mathrm{mg} / \mathrm{dL}$ or an increase $\geq 25 \%$ from baseline within $72 \mathrm{~h}$. (2) CA-AKI ${ }^{\mathrm{B}}$ was defined as an absolute increase of $\geq 0.3 \mathrm{mg} / \mathrm{dL}$ or a relative increase of $\geq 50 \%$ in $\mathrm{SCr}$ from baseline values within $72 \mathrm{~h}$. (3) CA-AKIC was defined as an absolute increase of $\geq 0.3 \mathrm{mg} / \mathrm{dL}$ or a relative increase of $\geq 50 \%$ in $\mathrm{SCr}$ from baseline values within 7 days.

\section{Data Analysis}

Analyses were performed using Stata version 12.0 (STATA, College Station, TX, USA) and R software (version 3.6.1; R Core Team, Vienna, Austria). Heterogeneity was calculated by the $\chi^{2}$ test considering the $I^{2}$ index to classify the degree of heterogeneity within those studies. When the heterogeneity was calculated $\left(I^{2} \geq\right.$ $50 \%)$, we used a random-effects model. Otherwise, the fixed-effects model was used if homogeneity was present $\left(I^{2} \leq 50 \%\right)$. According to the procedure, studies' clinical setting, and definition of CA-AKI, we completed subgroup analysis. We did sensitivity analysis by leaving one out to identify the source of heterogeneity. The pooled aOR from cohort studies was calculated with the $95 \%$ confidence interval. Additionally, publication bias was tested by both Begg's and Egger's tests. Publication bias was considered significant when $p<0.05$.

\section{Results}

\section{Study Selection and Study Characteristics}

After deleting duplicate articles, the initial search results left 23,782 articles. A total of 2,442 articles met the search criteria, and we read the full texts to determine whether they should be included in our meta-analysis. Through deep reading, we finally selected 45 articles discussing the relationship between HT and CA-AKI, which included 2,830,338 patients (Fig. 1) [5, 6, 9-13, 15-51]. Table 1 summarized the characteristics of the 45 studies, and the overall average incidence of CA-AKI was $6.48 \%$ $(n=183,395)$. 


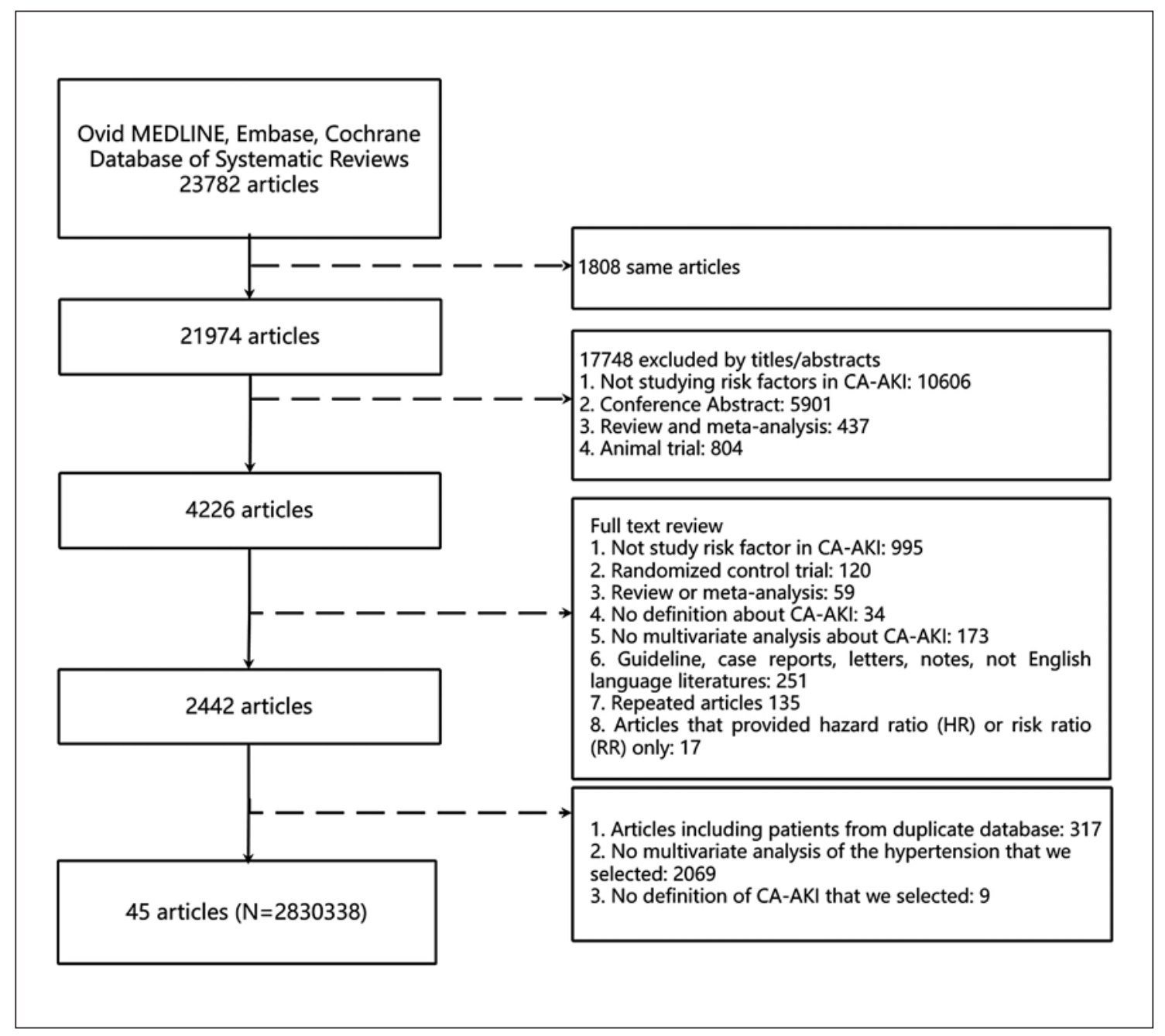

Fig. 1. Study selection.

According to the definitions of CA-AKI in these studies, there are 33 studies defined by $\mathrm{CA}-\mathrm{AKI}^{\mathrm{A}}, 8$ studies defined by $\mathrm{CA}-\mathrm{AKI}^{\mathrm{B}}$, and 12 defined by $\mathrm{CA}-\mathrm{AKI}^{\mathrm{C}}$. In the PCI subgroup analysis, we included 22 studies. In acute coronary syndrome (ACS), acute myocardial infarction (AMI), and ST-segment myocardial infarction (STEMI) subgroup analysis, 15 studies, 12 studies, and 7 studies were included respectively.

\section{Quality Assessment}

The articles included in our research were all highquality articles, of which 32 articles were judged as 9 points, 15 articles as 8 points, and the rest as 7 points. Detailed scores for each article with regard to the selection, compatibility, and outcome can be seen in online suppl. Table 1.

\section{$H T$ and $C A-A K I$}

We performed a meta-analysis based on aOR from the original study and confirmed that $\mathrm{HT}$ was associated with an increased risk of CA-AKI ${ }^{\mathrm{A}}$ (aOR: 1.378, 95\% CI: 1.211-1.567). A similar relationship was also found in CA-AKI ${ }^{\mathrm{B}}$ (aOR: 1.414, 95\% CI: 1.152-1.736) and CA-AKI ${ }^{\mathrm{C}}$ (aOR: 1.317, 95\% CI: 1.049-1.654) (Table 2; Fig. 2).

According to the CA-AKI ${ }^{\mathrm{A}}$ standard, we observed that HT increases the risk of CA-AKI (aOR: 1.403, 95\% CI: 1.182-1.666) in patients undergoing PCI (Table 2; Fig. 3). In ACS patients, we found that HT is an independent risk factor for CA-AKI (aOR: 1.328, 95\% CI: 1.077-1.637), the similar results were observed in patients with AMI (aOR: 1.325, 95\% CI: 1.017-1.727) and STEMI (aOR: 1.374, 95\% CI: 1.010-1.869) (Table 2; 


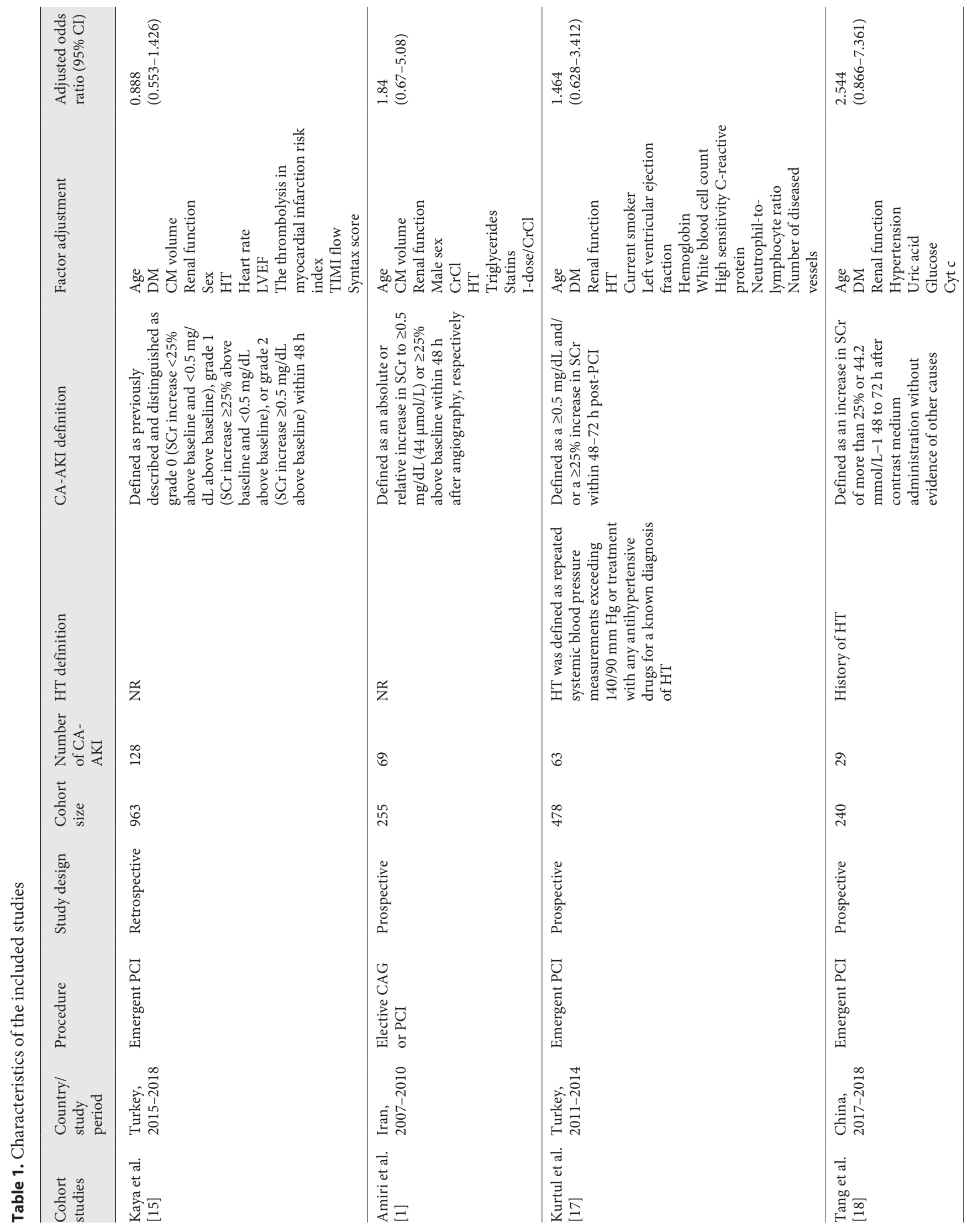




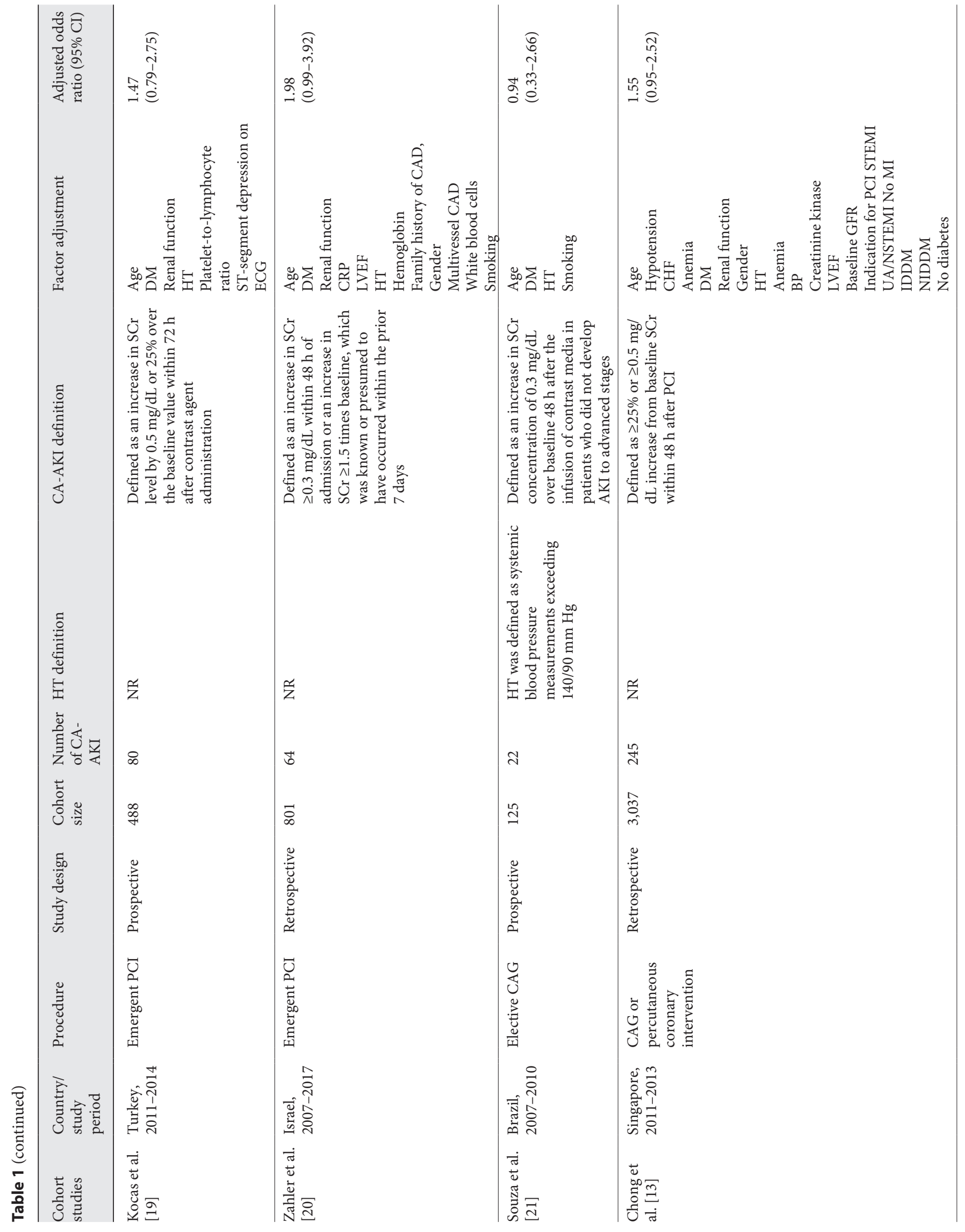




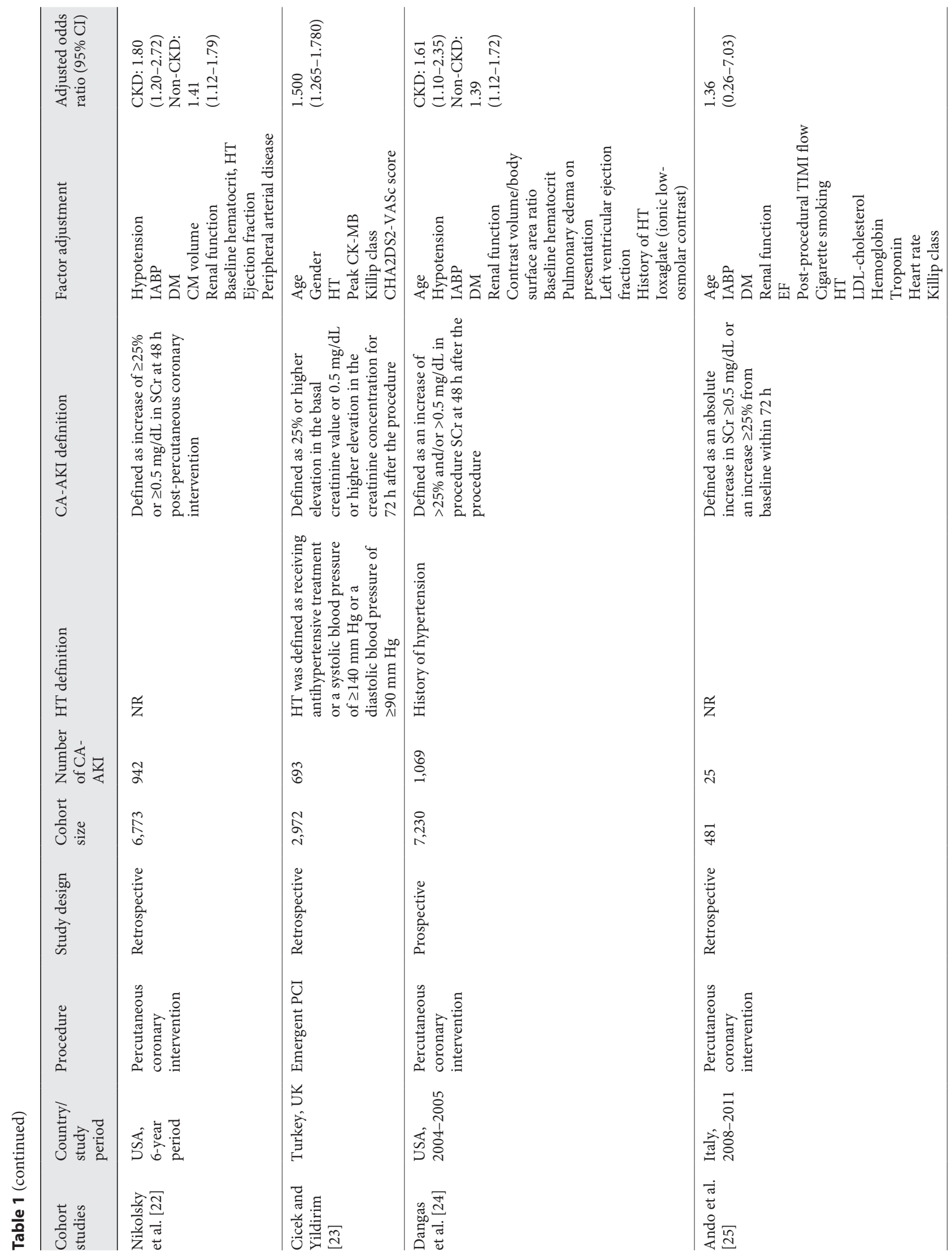




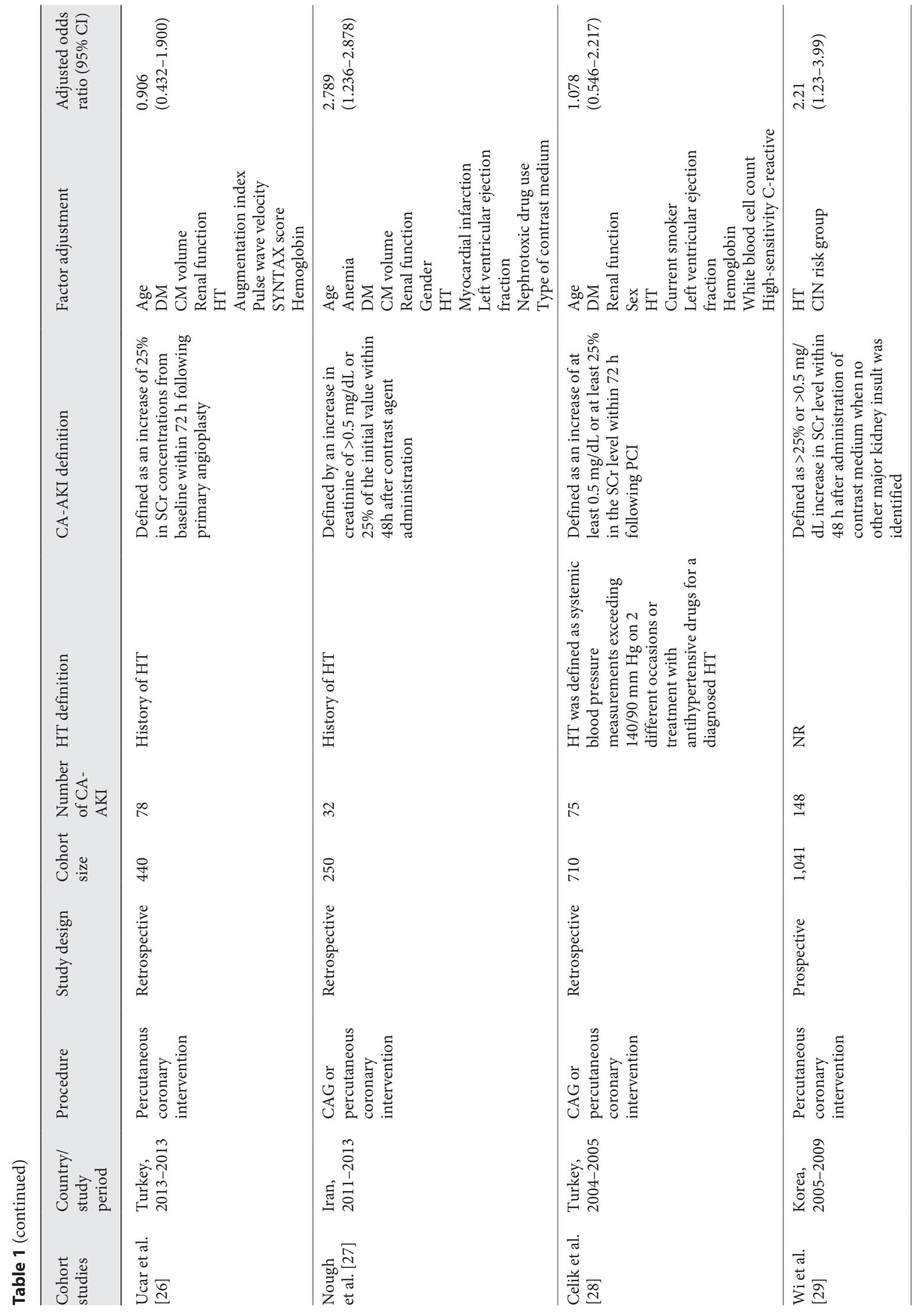




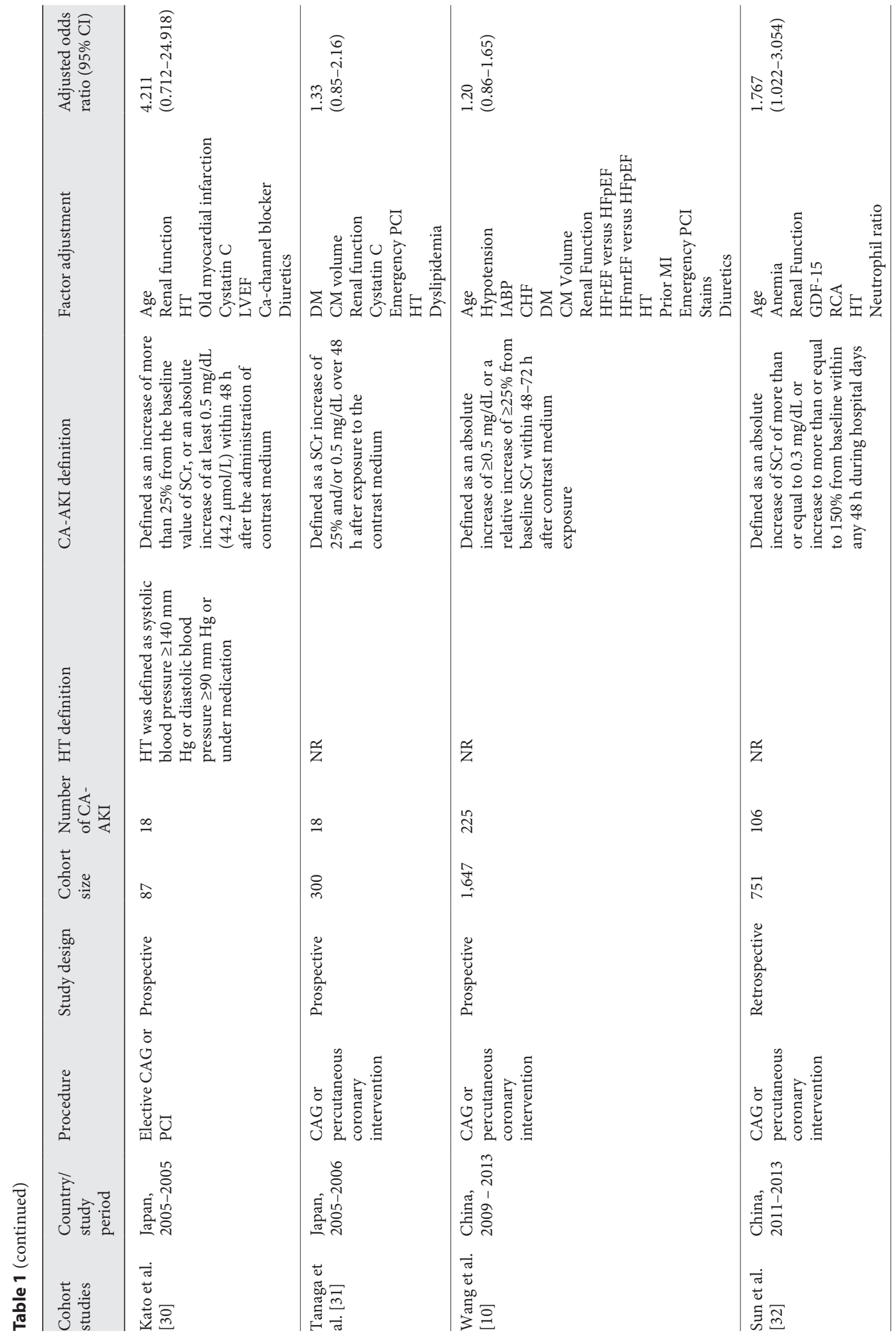




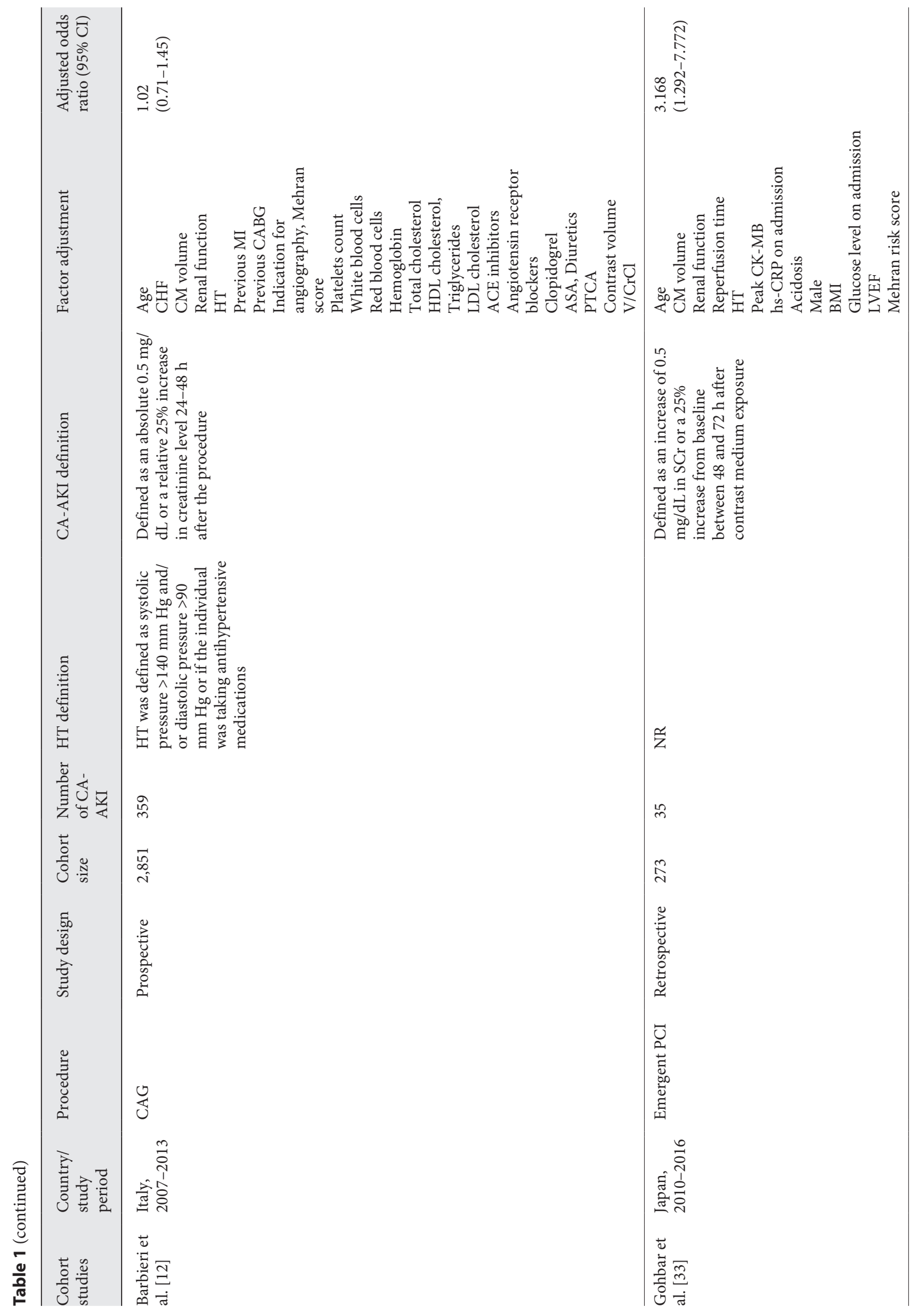




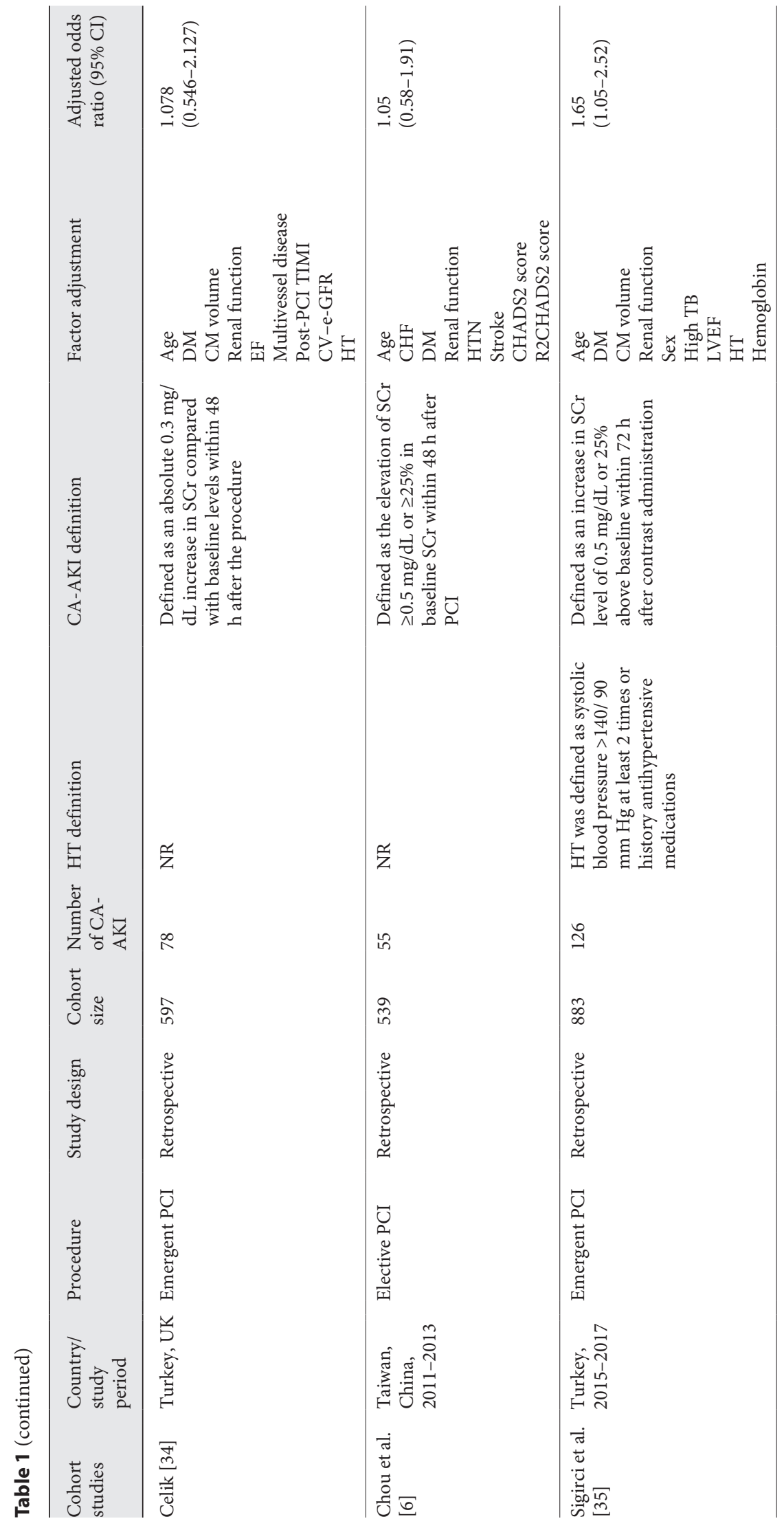









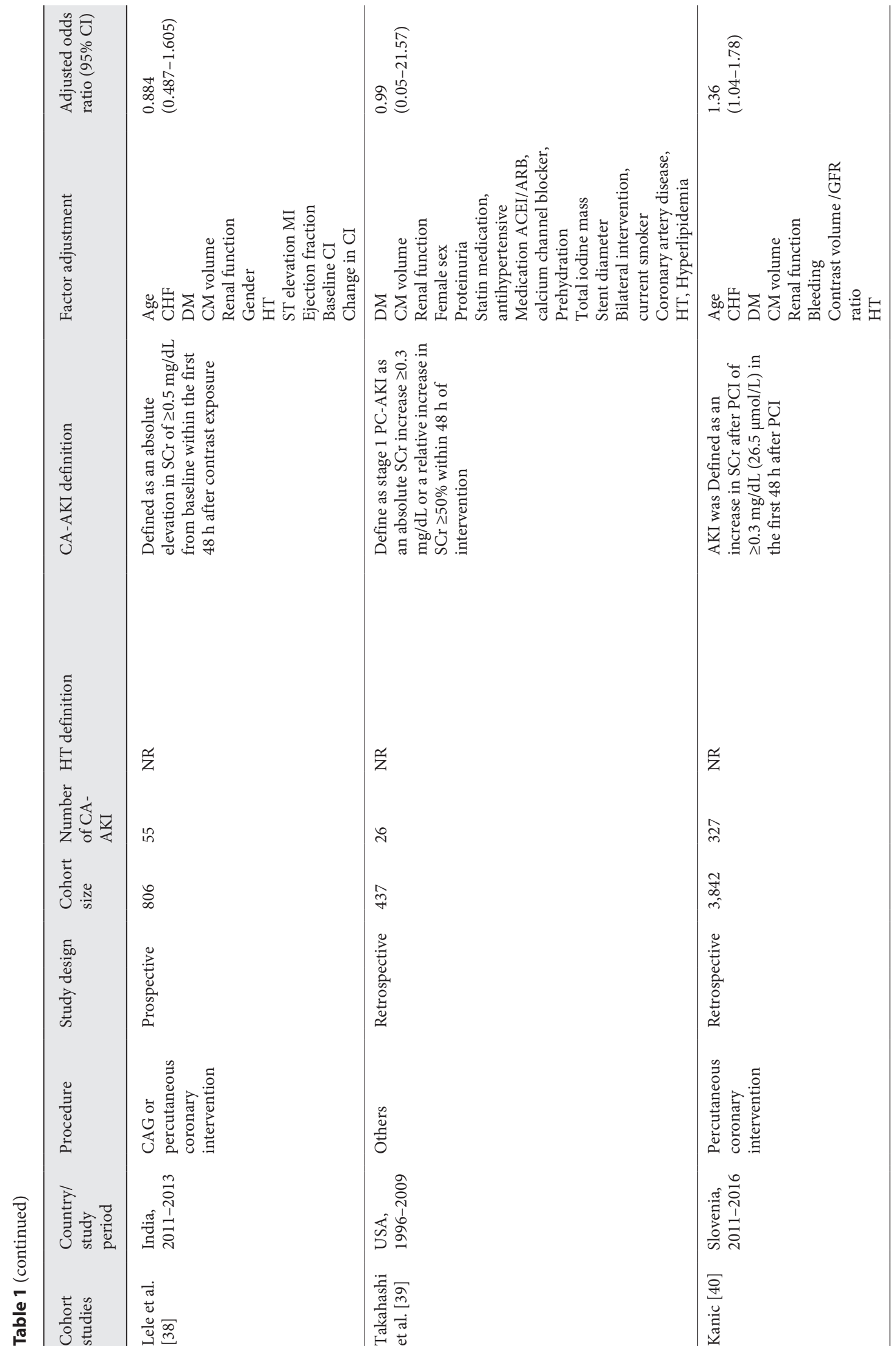




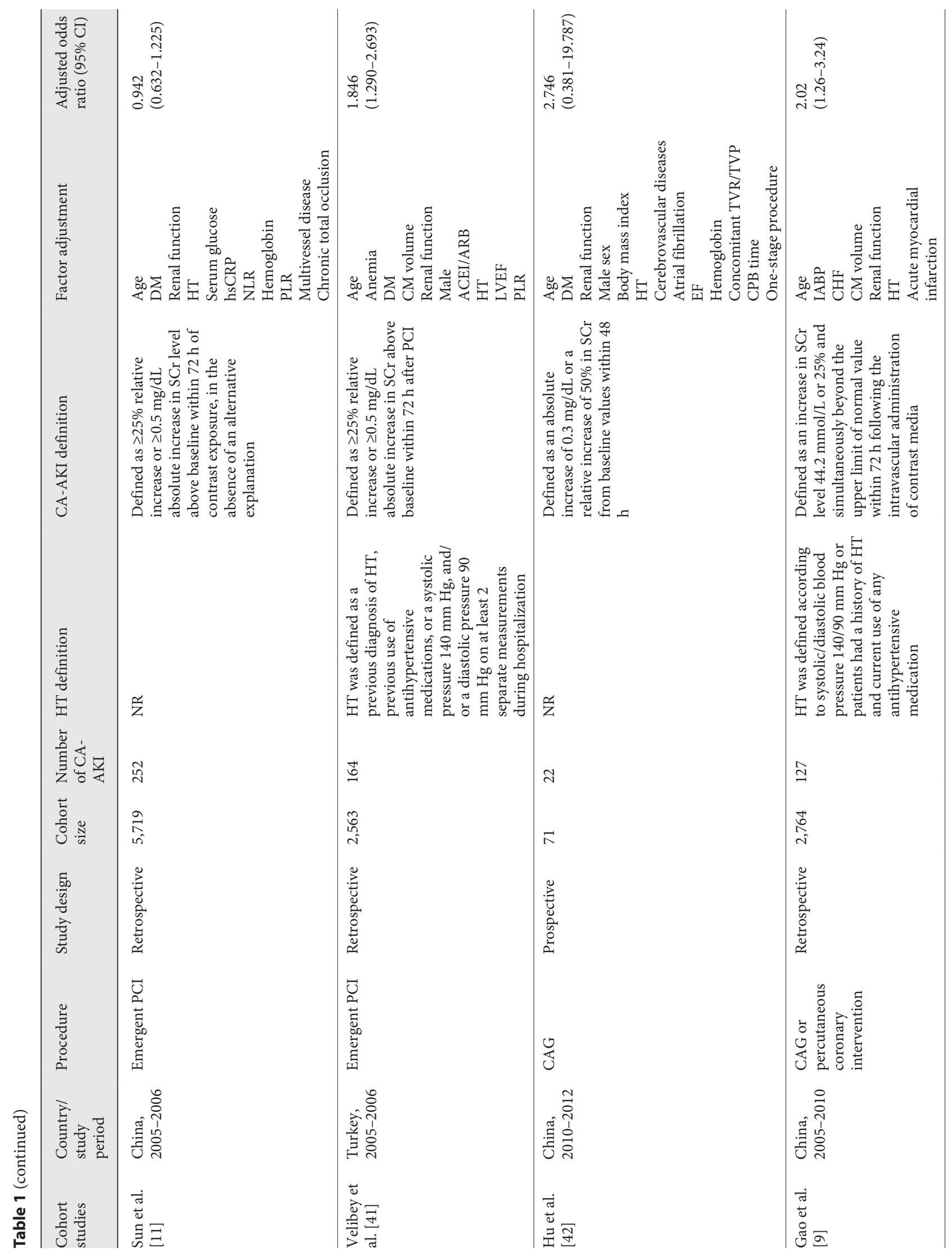




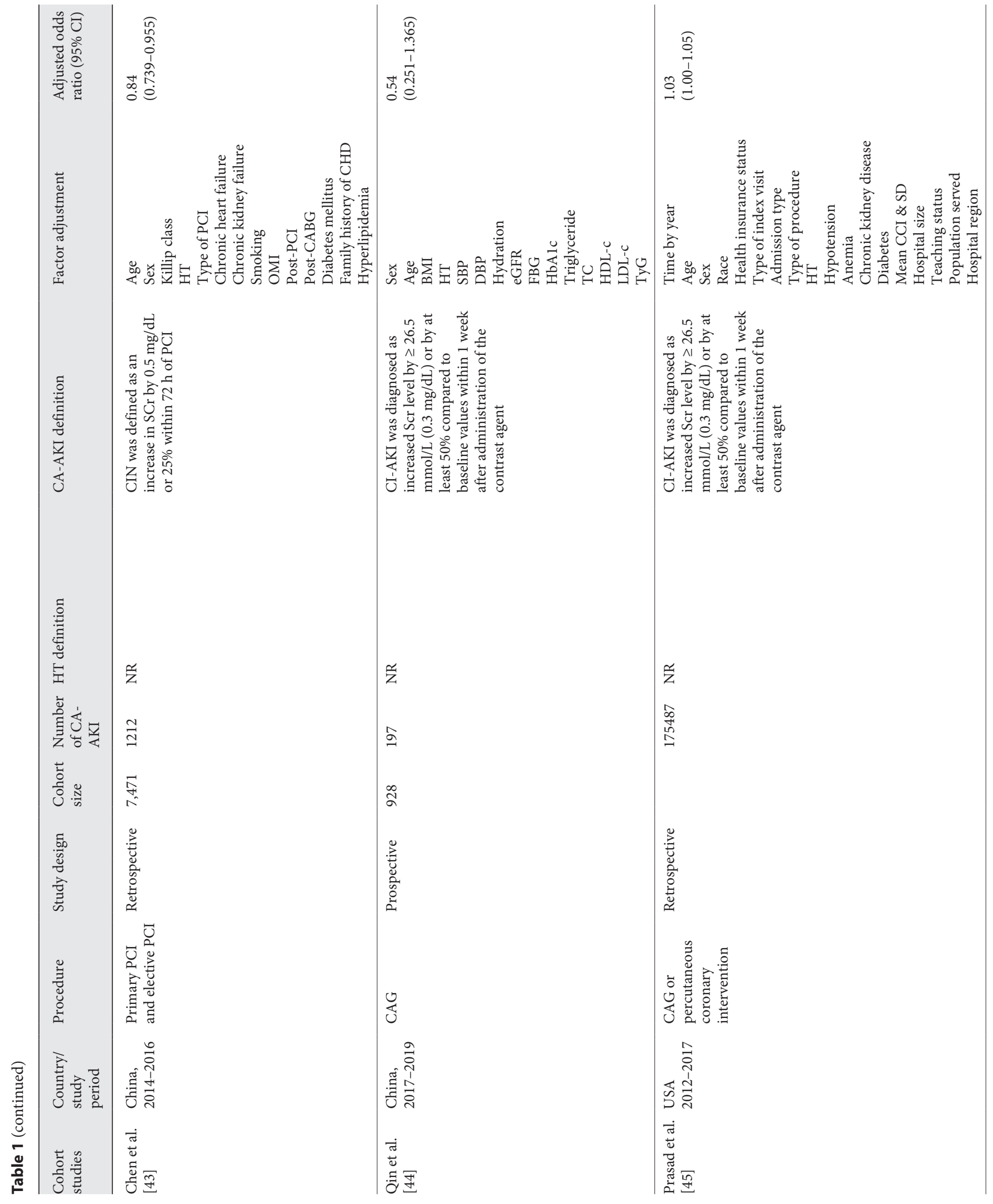




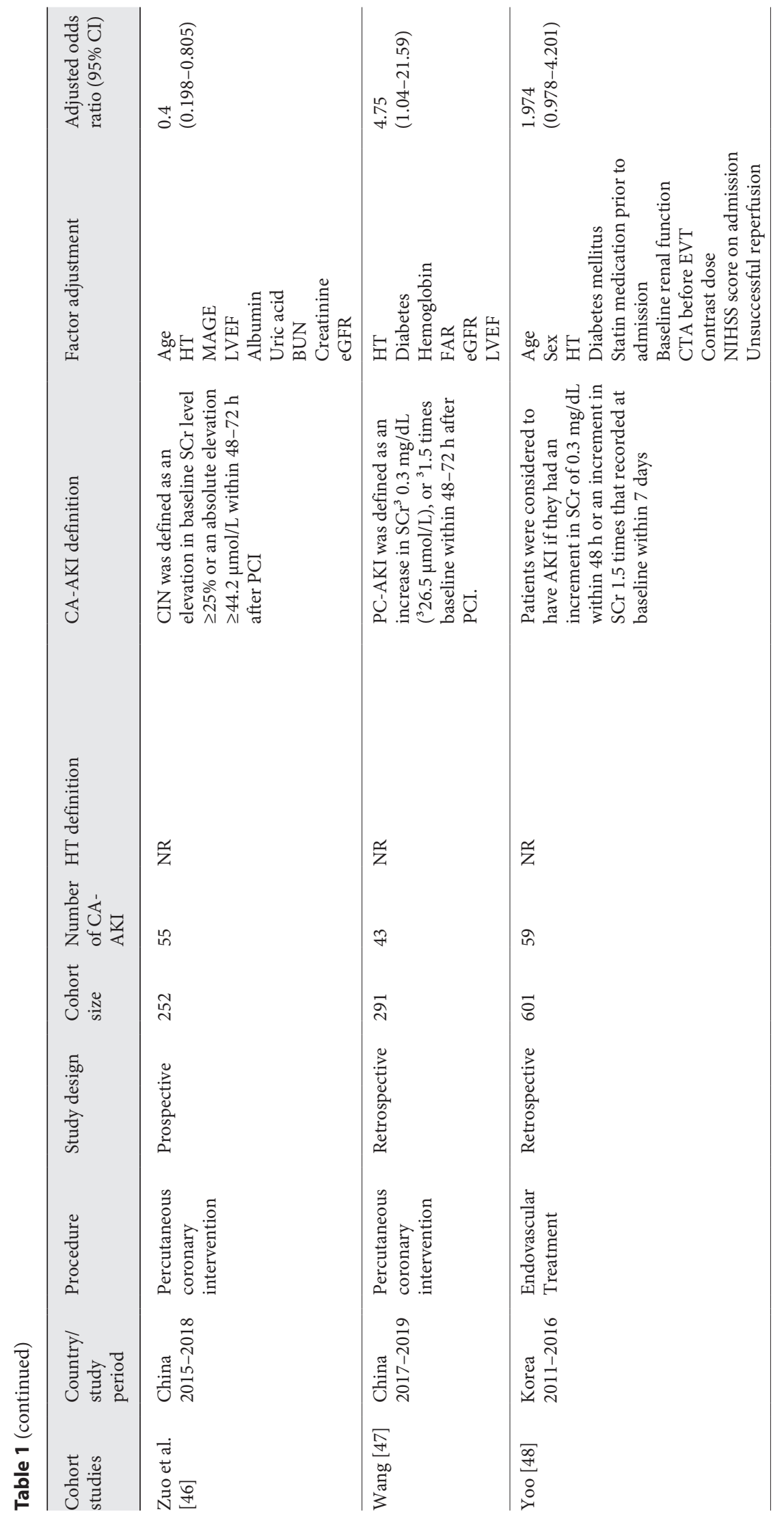




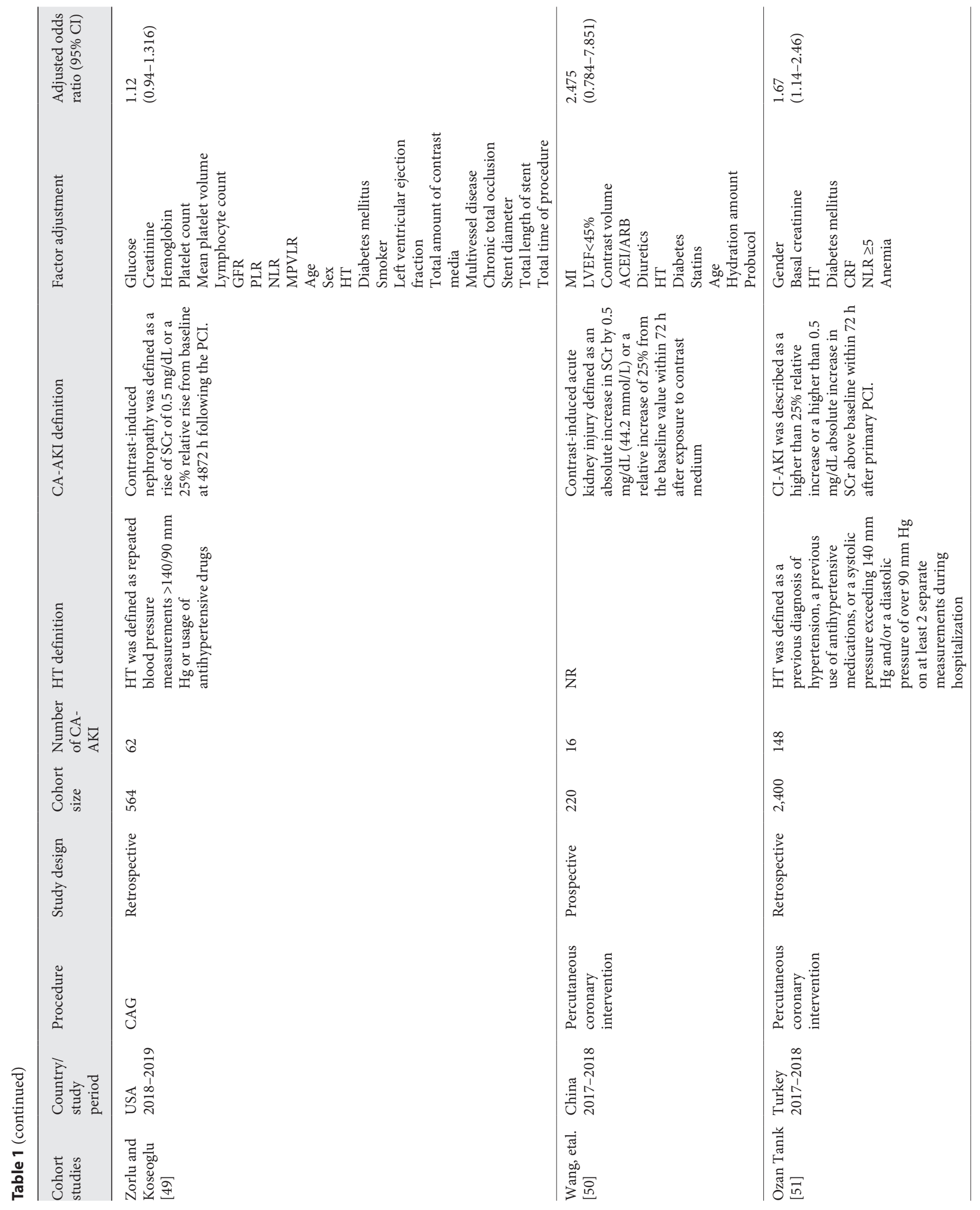




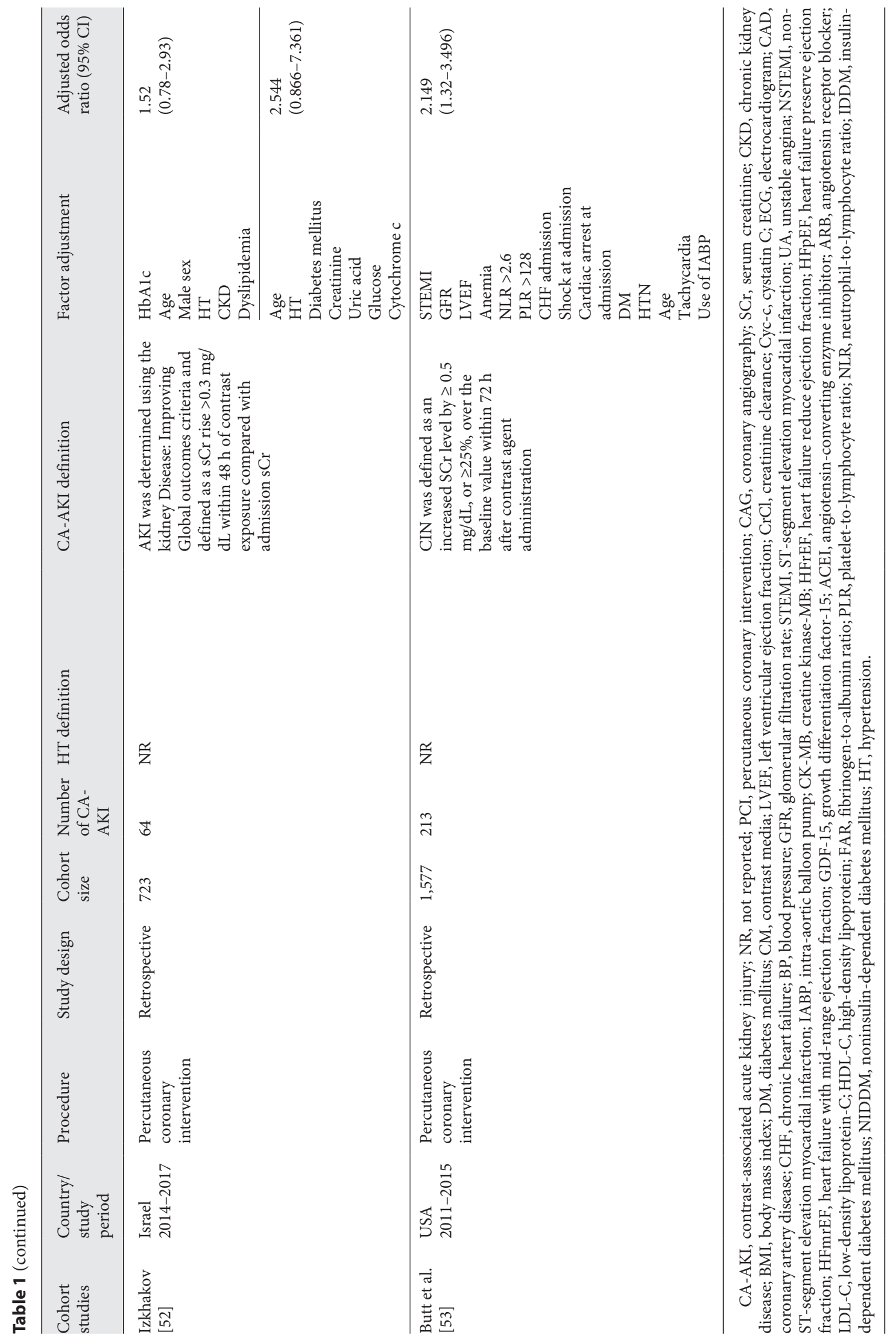




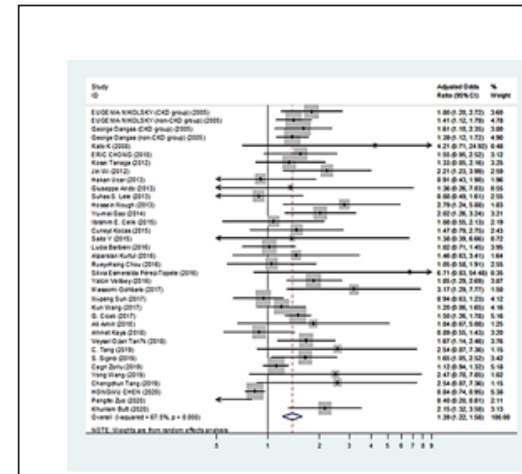

(A)

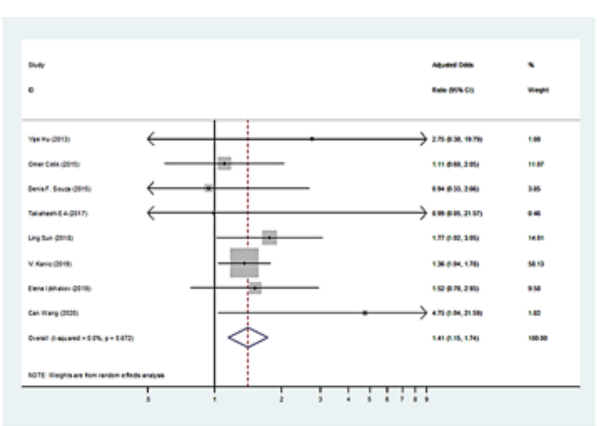

(B)

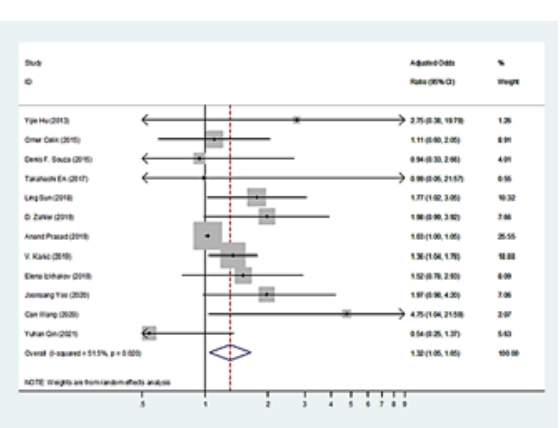

(C)
Fig. 2. Forest plot of the association between HT and risk of CAAKI. HT, hypertension. A CA-AKI ${ }^{\mathrm{A}}, \mathrm{CA}-\mathrm{AKI}^{\mathrm{A}}$ was defined as an absolute increase in SCR $\geq 0.5 \mathrm{mg} / \mathrm{dL}$ or an increase $\geq 25 \%$ from baseline within $72 \mathrm{~h}$. B CA-AKI ${ }^{\mathrm{B}}, \mathrm{CA}-\mathrm{AKI}^{\mathrm{B}}$ was defined as an absolute increase of $\geq 0.3 \mathrm{mg} / \mathrm{dL}$ or a relative increase of $\geq 50 \%$ in $\mathrm{SCr}$ from baseline values within 72 h. C CA-AKI ${ }^{\mathrm{C}}, \mathrm{CA}-\mathrm{AKI}{ }^{\mathrm{C}}$ was defined as an absolute increase of $\geq 0.3 \mathrm{mg} / \mathrm{dL}$ or a relative increase of $\geq 50 \%$ in SCr from baseline values within 7 days. SCr, serum creatinine.

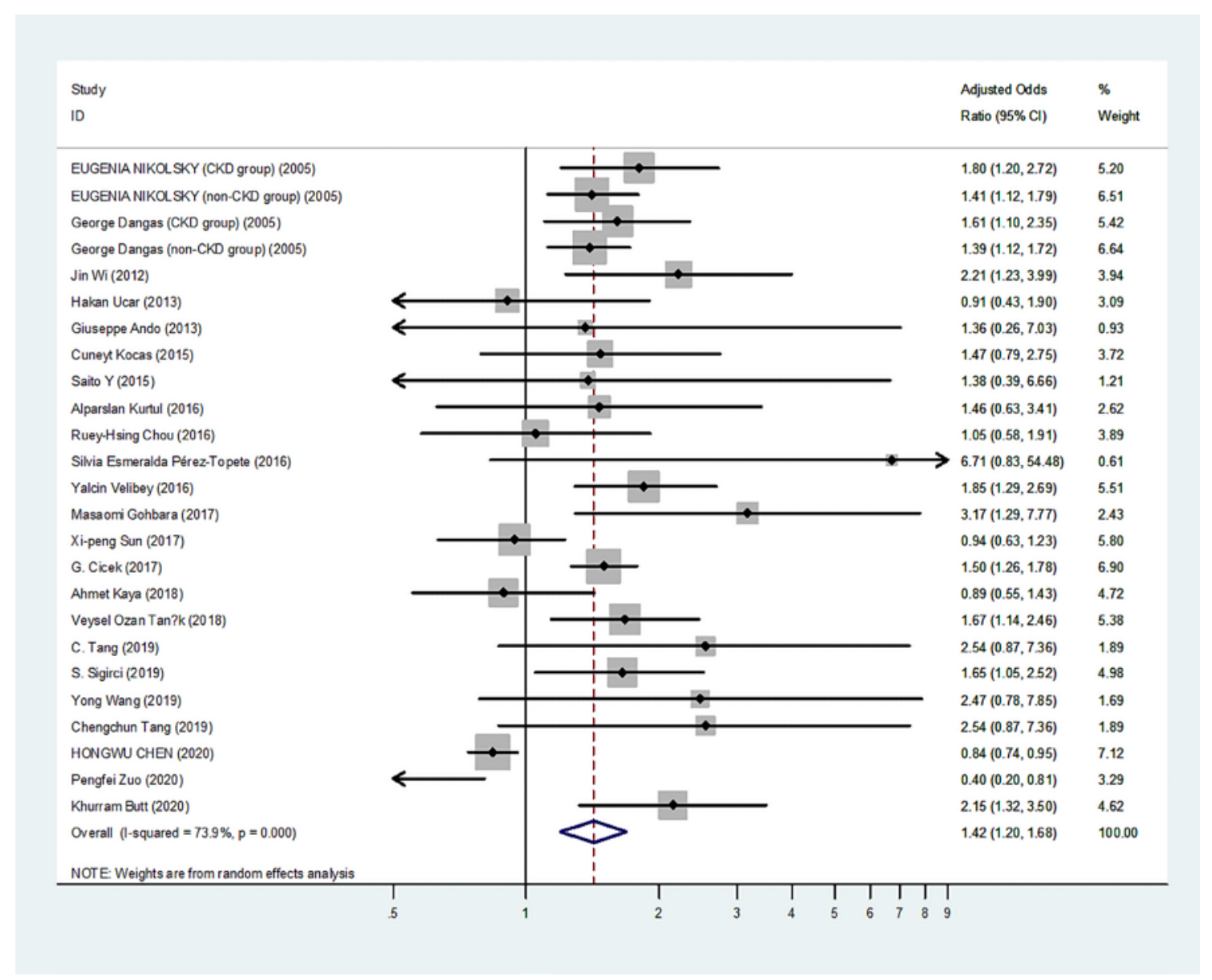

Fig. 3. Forest plot of the association between $\mathrm{HT}$ and risk of CA-AKI ${ }^{\mathrm{A}}$ in patients with PCI. CA-AKI ${ }^{\mathrm{A}}$ was defined as an absolute increase in $\mathrm{SCr} \geq 0.5 \mathrm{mg} / \mathrm{dL}$ or an increase $\geq 25 \%$ from baseline within $72 \mathrm{~h}$. HT, hypertension; SCr, serum creatinine.

A Meta-Analysis of Contrast-Associated Acute Kidney Injury and Hypertension 


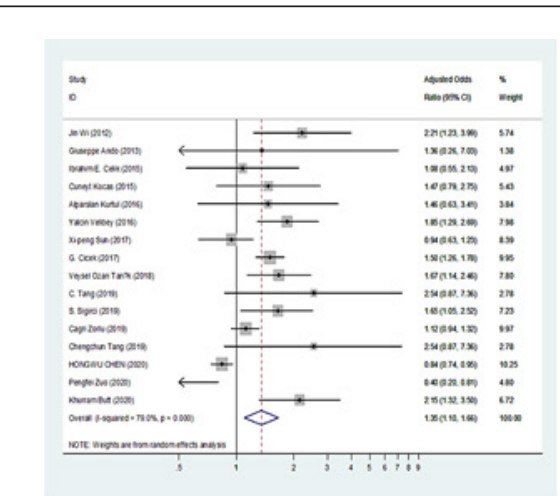

(A)

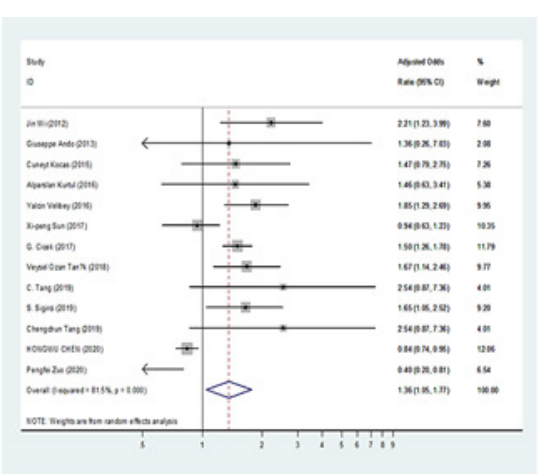

(B)

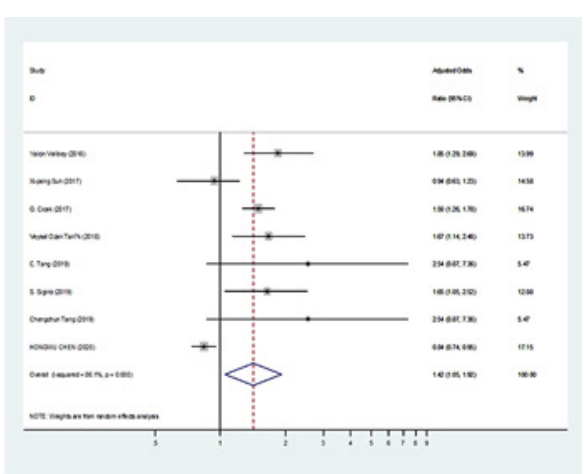

(C)
Fig. 4. Forest plot of the association between $\mathrm{HT}$ and risk of CA$\mathrm{AKI}^{\mathrm{A}}$ in patients with clinical setting. CA-AKI ${ }^{\mathrm{A}}$ was defined as an absolute increase in $\mathrm{SCr} \geq 0.5 \mathrm{mg} / \mathrm{dL}$ or an increase $\geq 25 \%$ from baseline within $72 \mathrm{~h}$. A The patients with ACS. B The patients with
AMI. C The patients with STEMI. ACS, acute coronary syndrome; AMI, acute myocardial infarction; STEMI, ST-segment myocardial infarction; HT, hypertension; SCr, serum creatinine.

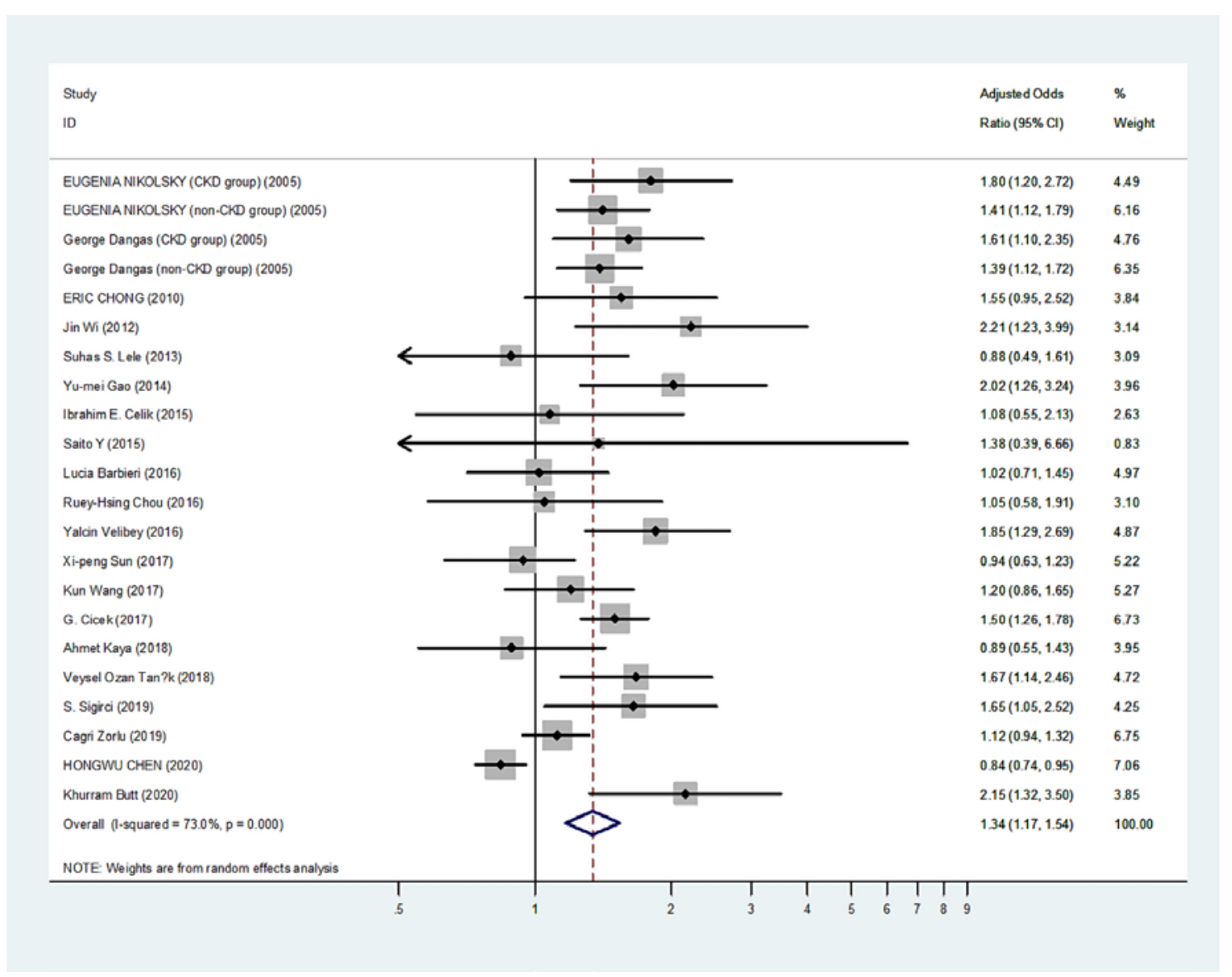

Fig. 5. Forest plot of the association between $\mathrm{HT}$ and risk of $\mathrm{CA}-\mathrm{AKI} \mathrm{I}^{\mathrm{A}}$ with the sample size of $\geq 500$. CA-AKI was defined as an absolute increase in $\mathrm{SCr} \geq 0.5 \mathrm{mg} / \mathrm{dL}$ or an increase $\geq 25 \%$ from baseline within $72 \mathrm{~h}$. HT, hypertension; SCr, serum creatinine. 
Table 2. Pooled odds ratio of HT for CA-AKI

\begin{tabular}{lrrrrr}
\hline & Studies & $\begin{array}{l}\text { Total } \\
\text { patients }\end{array}$ & $\begin{array}{l}\text { Cases of } \\
\text { CA-AKI }\end{array}$ & $\begin{array}{l}\text { Pooled adjusted odds } \\
\text { ratio }\end{array}$ & $I^{2}$ index, \% \\
\hline CA-AKI & 34 & 57,490 & 6,900 & $1.388(1.220-1.578)$ & 67.5 \\
CA-AKI & 8 & 6,837 & 688 & $1.414(1.152-1.736)$ & 0 \\
CA-AKI & 12 & $2,772,848$ & 176,495 & $1.317(1.049-1.654)$ & 51.5 \\
Subgroup analysis for CA-AKI & & & & & 73.9 \\
$\quad \begin{array}{l}\text { Procedure } \\
\quad \text { PCI }\end{array}$ & 23 & 44,219 & 5,515 & $1.419(1.197-1.683)$ & 79.0 \\
$\quad \begin{array}{l}\text { Studies' clinical setting } \\
\quad \text { ACS }\end{array}$ & 16 & 28,079 & 3,374 & $1.353(1.100-1.664)$ & 7.5 \\
$\quad$ AMI & 13 & 25,228 & 3,024 & $1.361(1.049-1.766)$ & 81.5 \\
$\quad$ STEMI & 8 & 22,488 & 2,653 & $1.422(1.052-1.921)$ & 86.1 \\
\hline
\end{tabular}

CA-AKI, contrast-associated acute kidney injury; PCI, percutaneous coronary intervention; AMI, acute myocardial infarction; ACS, acute coronary syndrome; STEMI, ST-segment myocardial infarction; SCr, serum creatinine; HT, hypertension.

Fig. 4). When we included studies with a sample size of $\geq 500$ into the analysis, we found that there is still a significant correlation between HT and CA-AKI (aOR: 1.341, 95\% CI: 1.170-1.537) (Table 2; Fig. 5).

\section{Sensitivity Analysis and Publication Bias}

In the process of exploring heterogeneity in the metaanalysis, the heterogeneity was $67.9 \%, 0 \%$, and $51.5 \%$ in 3 definitions of CA-AKI, so we kept all the articles. No publication bias was found in CA-AKI ${ }^{\mathrm{A}}$ (Begg's test: $p=$ 0.513 and Egger's test: $p=0.006$ ), CA-AKI ${ }^{\mathrm{B}}$ (Begg's test: $p=0.711$ and Egger's test: $p=0.445)$, and $\mathrm{CA}-\mathrm{AKI}^{\mathrm{C}}$ (Begg's test: $p=0.631$ and Egger's test: $p=0.027$ ), and the funnel plot is shown in online suppl. Figure 1.

\section{Discussion}

This is the first meta-analysis of HT as a risk factor for CA-AKI, and we found that HT is an independent risk factor of CA-AKI ${ }^{\mathrm{A}}$ (aOR: 1.378, 95\% CI: 1.211-1.567). At the same time, we got similar results for $\mathrm{CA}-\mathrm{AKI}^{\mathrm{B}}$ (aOR: 1.414, 95\% CI: 1.152-1.736) and CA-AKI ${ }^{\mathrm{C}}$ (aOR: 1.317, 95\% CI: 1.049-1.654), which further confirmed our analysis.

In our study, the average incidence rate was $6.48 \%$, similar to that reported by Chalikias [52]. When we pooled aOR from 45 articles, we found that an increased risk of CA-AKI associated with HT (aOR: 1.341, 95\% CI: $1.170-1.537)$. This is similar to the view reported in a recent article about CA-AKI published by Kanic et al. [40].
The reason may be that most of the patients undergoing percutaneous coronary intervention included in our meta-analysis, which is very similar to Kanic's study. In a meta-analysis that evaluated the risk of AKI after cardiovascular surgery, HT was also an important preoperative factor [53]. However, the OR was slightly higher than that in ours because the definition of AKI in their article used the RIFLE criteria. In addition, we have observed similar results in ACS, AMI, and other patients, which further confirms our view. We also increased the credibility of our results by analyzing different definitions of CA-AKI.

At present, few studies have clearly explained the mechanism that HT increases the risk of CA-AKI. The major mechanism may be that hemodynamic perturbations damage renal arterioles and glomeruli, thereby reducing the tolerance of the kidney to nephrotoxic drugs and increasing the risk of CA-AKI. At the same time, vasoactive substances such as endothelin, nitric oxide, and prostaglandins also participate in the mechanism [5456].

Our research confirms that HT can increase the risk of CA-AKI, which means the use of antihypertensive drugs before surgery can reduce the risk of CA-AKI. Recently, Nguyen et al. [57] found that the use of ACEI/ ARB in STEMI patients can effectively reduce the occurrence of CA-AKI. However, some studies have observed that the relationship between the use of ACEI/ARB and CA-AKI is still unclear $[12,58]$. Even some studies found that using ACEI/ARB can increase the risk of CA-AKI $[41,59]$. A large meta-analysis was still needed to resolve 
this contradiction. Liu et al. [60] found that early $\beta$-blocker administration is associated with a reduced risk of contrast-induced acute kidney injury in patients with AMI. Although diuretics can lower blood pressure, Shiba et al. [61] found that diuretics can increase the risk of acute kidney injury, which may be related to renal microcirculation and perfusion disorders. The relationship between calcium channel blockers and CA-AKI was still unclear, and a large cohort study is needed to confirm in the future $[62,63]$. These studies showed that the preoperative use of antihypertensive drugs may not be effective in reducing the risk of CA-AKI. So we should take active preventive measures recommended by the current guidelines for patients with HT to reduce the occurrence of CA-AKI.

Our research had several limitations. First, the data of this study came from a systematic database that studying the risk factors of CA-AKI. It does not originate from the initial search for articles that study the relationship between HT and CA-AKI. However, the heterogeneity of our research was low, which makes our results have more credibility. Second, the definitions of CA-AKI are various. We cannot complete the subgroup analysis of CA-AKI under multiple different definitions, which may reduce the generality of our results. But we have also completed the subgroup analysis of 2 common definitions and found consistency with the main analysis. Third, due to the limitation of the design and the number of studies included, we cannot evaluate the relationship between HT and CA-AKI in different disease states. But we also confirmed that HT is an independent risk factor of CA-AKI in the high-risk group of CA-AKI (ACS, AMI, and STEMI). Future research is still needed to clarify the relationship between HT and diabetes in more disease states (diabetes, chronic kidney disease, and heart failure).

\section{Conclusion}

In our meta-analysis, we found that HT is an independent risk factor for CA-AKI. In clinical practice, we should pay more attention to patients with HT and take active preventive measures.

\section{Statement of Ethics}

This meta-analysis was approved by the Ethics Committee of Guangdong Provincial People's Hospital. The work was conducted in accordance with the Declaration of Helsinki.

\section{Conflict of Interest Statement}

The authors have no conflicts of interest to declare.

\section{Funding Sources}

The study is supported by the National Natural Science Foundation of China (Grant Nos. 81670339 and 81970311), the Beijing Lisheng Cardiovascular Pilot Foundation (Grant No. LHJJ201612127), and the Science and Technology Planning Project of Guangdong Province (Grant No. 2014B070706010), the Science and Technology Planning Project of Guangzhou (Grant No. 201704020124), Guangdong Provincial Fund for Clinical Medications (2019ZH01), high-level talent team-building project (Y012018085), and Dengfeng Project in Guangdong Province (DFJH201919 and DFJH2020026).

\section{Author Contributions}

Conception and design of the meta-analysis: J.C., J.Y., and Y.L. Performance of the meta-analysis: Z.L., J.Y., and Y.L. Quality assessment of the meta-analysis: Z.L., Z.M., L.L., G.C., H.L., M.Y., B.W., and Y.Y. Analysis of study data: Z.L., Z.M., S.C., and JL. Writing of the paper: Z.L., Z.M., L.L., and G.C. All authors have read and approved the final version of the manuscript.

\section{References}

1 Deek H, Newton P, Sheerin N, Noureddine S, Davidson PM. Contrast media induced nephropathy: a literature review of the available evidence and recommendations for practice. Aust Crit Care. 2014;27(4):166-71.

2 Allen DW, Ma B, Leung KC, Graham MM, Pannu N, Traboulsi M, et al. Risk prediction models for contrast-induced acute kidney injury accompanying cardiac catheterization: systematic review and meta-analysis. Can J Cardiol. 2017;33(6):724-36.

3 Mehran R, Dangas GD, Weisbord SD. Contrast-associated acute kidney injury. $\mathrm{N}$ Engl J Med. 2019;380(22):2146-55.
4 Watabe H, Sato A, Hoshi T, Takeyasu N, Abe $\mathrm{D}$, Akiyama $\mathrm{D}$, et al. Association of contrastinduced acute kidney injury with long-term cardiovascular events in acute coronary syndrome patients with chronic kidney disease undergoing emergent percutaneous coronary intervention. Int J Cardiol. 2014;174(1):57-63.

5 Yang Y, George KC, Luo R, Cheng Y, Shang $\mathrm{W}, \mathrm{Ge}$ S, et al. Contrast-induced acute kidney injury and adverse clinical outcomes risk in acute coronary syndrome patients undergoing percutaneous coronary intervention: a meta-analysis. BMC Nephrol. 2018;19(1): 374.
6 Chou RH, Huang PH, Hsu CY, Leu HB, Huang SS, Huang CC, et al. CHADS2 score predicts risk of contrast-induced nephropathy in stable coronary artery disease patients undergoing percutaneous coronary interventions. J Formos Med Assoc. 2016;115(7):5019.

7 Brown JR, MacKenzie TA, Maddox TM, Fly J, Tsai TT, Plomondon ME, et al. Acute kidney injury risk prediction in patients undergoing coronary angiography in a national veterans health administration cohort with external validation. J Am Heart Assoc. 2015;4(12): e002136. 
8 Inohara T, Kohsaka S, Abe T, Miyata $\mathrm{H}, \mathrm{Nu}$ masawa Y, Ueda I, et al. Development and validation of a pre-percutaneous coronary intervention risk model of contrast-induced acute kidney injury with an integer scoring system. Am J Cardiol. 2015;115(12):1636-42.

9 Gao YM, Li D, Cheng H, Chen YP. Derivation and validation of a risk score for contrast-induced nephropathy after cardiac catheterization in Chinese patients. Clin Exp Nephrol. 2014;18(6):892-8.

10 Wang K, Li HL, Bei WJ, Guo XS, Chen SQ, Islam SMS, et al. Association of left ventricular ejection fraction with contrast-induced nephropathy and mortality following coronary angiography or intervention in patients with heart failure. Ther Clin Risk Manag. 2017;13:887-95.

11 Sun XP, Li J, Zhu WW, Li DB, Chen H, Li HW, et al. Platelet to lymphocyte ratio predicts contrast-induced nephropathy in patients with ST-segment elevation myocardial infarction undergoing primary percutaneous coronary intervention. Angiology. 2018;69(1):71-8.

12 Barbieri L, Verdoia M, Nardin M, Marino P, Suryapranata H, De Luca G. Gender difference in the risk of contrast-induced nephropathy in patients undergoing coronary angiography or percutaneous coronary intervention. Angiology. 2017;68(6):542-6.

13 Chong E, Poh KK, Liang S, Soon CY, Tan HC. Comparison of risks and clinical predictors of contrast-induced nephropathy in patients undergoing emergency versus nonemergency percutaneous coronary interventions. J Interv Cardiol. 2010;23(5):451-9.

14 Stroup DF, Berlin JA, Morton SC, Olkin I, Williamson GD, Rennie D, et al. Meta-analysis of observational studies in epidemiology: a proposal for reporting. Meta-analysis Of observational studies in epidemiology (MOOSE) group. JAMA. 2000;283(15):2008-12.

15 Kaya A, Karataş A, Kaya Y, Düğeroğlu H, Dereli S, Bayramoğlu A. A new and simple risk predictor of contrast-induced nephropathy in patients undergoing primary percutaneous coronary intervention: TIMI risk index. Cardiol Res Pract. 2018;2018:5908215.

16 Amiri A, Ghanavati R, Riahi Beni H, Sezavar SH, Sheykhvatan M, Arab M. Metabolic Syndrome and the iodine-dose/creatinine clearance ratio as determinants of contrast-induced acute kidney injury. Cardiorenal Med. 2018;8(3):217-27.

17 Kurtul A, Yarlioglues M, Duran M, Murat SN. Association of neutrophil-to-lymphocyte ratio with contrast-induced nephropathy in patients with Non-ST-elevation acute coronary syndrome treated with percutaneous coronary intervention. Heart Lung Circ. 2016; 25(7):683-90.

18 Tang C, Hou J, Yan G, Qiao Y, Wang D, Zhu $B$, et al. Effects of serum cytochrome c on contrast-induced nephropathy in patients with ST-elevation myocardial infarction undergoing percutaneous coronary intervention. Biomed Res Int. 2019;2019:9357203.
19 Kocas C, Yildiz A, Abaci O, Karaca OS, Firdin $\mathrm{N}$, Dalgic Y, et al. Platelet-to-lymphocyte ratio predicts contrast-induced nephropathy in patients with Non-ST-segment elevation acute coronary syndrome. Angiology. 2015; 66(10):964-8.

20 Zahler D, Rozenfeld KL, Stein M, Milwidsky A, Berliner S, Banai S, et al. C-reactive protein velocity and the risk of acute kidney injury among ST elevation myocardial infarction patients undergoing primary percutaneous intervention. J Nephrol. 2019;32(3):437-43.

21 Souza DF, Reis SS, Botelho RV, Ferreira-Filho SR. Relative and absolute changes in urinary neutrophil gelatinase-associated lipocalin and correlation with small increases in serum creatinine levels after coronary angiography: an observational study. Nephron. 2015; 129(2):84-90.

22 Nikolsky E, Mehran R, Lasic Z, Mintz GS, Lansky AJ, Na Y, et al. Low hematocrit predicts contrast-induced nephropathy after percutaneous coronary interventions. Kidney Int. 2005;67(2):706-13.

23 Cicek G, Yıldırım E. CHA2DS2-VASc score predicts contrast-induced nephropathy in patients with ST-segment elevation myocardial infarction, who have undergone primary percutaneous coronary intervention. Kardiol Pol. 2018;76(1):91-8.

24 Dangas G, Iakovou I, Nikolsky E, Aymong ED, Mintz GS, Kipshidze NN, et al. Contrastinduced nephropathy after percutaneous coronary interventions in relation to chronic kidney disease and hemodynamic variables. Am J Cardiol. 2005;95(1):13-9.

25 Ando G, Morabito G, de Gregorio C, Trio O, Saporito F, Oreto G. Age, glomerular filtration rate, ejection fraction, and the AGEF score predict contrast-induced nephropathy in patients with acute myocardial infarction undergoing primary percutaneous coronary intervention. Catheter Cardiovasc Interv. 2013;82(6):878-85.

26 Ucar H, Gür M, Yildirim A, Börekçi A, Gözükara MY, Seker T, et al. Increased aortic stiffness predicts contrast-induced nephropathy in patients with stable coronary artery disease undergoing percutaneous coronary intervention. Angiology. 2014;65(9):806-11.

27 Nough H, Eghbal F, Soltani M, Nejafi F, Falahzadeh $\mathrm{H}$, Fazel $\mathrm{H}$, et al. Incidence and main determinants of contrast-induced nephropathy following coronary angiography or subsequent balloon angioplasty. Cardiorenal Med. 2013;3(2):128-35.

28 Celik IE, Kurtul A, Duran M, Yarlioglues M, Elcik D, Kilic A, et al. Elevated serum fibrinogen levels and risk of contrast-induced acute kidney injury in patients undergoing a percutaneous coronary intervention for the treatment of acute coronary syndrome. Coron Artery Dis. 2016;27(1):13-8.

29 Wi J, Ko YG, Shin DH, Kim JS, Kim BK, Choi $D$, et al. Prediction of contrast-induced nephropathy with persistent renal dysfunction and adverse long-term outcomes in patients with acute myocardial infarction using the mehran risk score. Clin Cardiol. 2013;36(1): 46-53.

30 Kato K, Sato N, Yamamoto T, Iwasaki YK, Tanaka K, Mizuno K. Valuable markers for contrast-induced nephropathy in patients undergoing cardiac catheterization. Circ J. 2008;72(9):1499-505.

31 Tanaga K, Tarao K, Nakamura Y, Inoue T, Jo $\mathrm{K}$, Ishikawa $\mathrm{T}$, et al. Percutaneous coronary intervention causes increase of serum cystatin C concentration even in the patients with a low risk of contrast-induced nephropathy. Cardiovasc Interv Ther. 2012;27(3):168-73.

32 Sun L, Zhou X, Jiang J, Zang X, Chen X, Li H, et al. Growth differentiation factor-15 levels and the risk of contrast induced acute kidney injury in acute myocardial infarction patients treated invasively: a propensity-score match analysis. PLoS One. 2018;13(3):e0194152.

33 Gohbara M, et al. Association between acidosis soon after reperfusion and contrast-induced nephropathy in patients with a firsttime ST-segment elevation myocardial infarction. J Am Heart Assoc. 2017;6(8): e006380.

34 Celik O, Ozturk D, Akin F, Ayca B, Yalcın AA, Erturk M, et al. Association between contrast media volume-glomerular filtration rate ratio and contrast-induced acute kidney injury after primary percutaneous coronary intervention. Angiology. 2015;66(6):519-24.

35 Sigirci S, Keskin K, Yildiz SS, Cetinkal G, Gurdal A, Kilci H, et al. Can thrombus burden predict contrast-induced nephropathy in patients with ST-segment elevation myocardial infarction? Angiology. 2019;70(7):642-8.

36 Saito Y, Watanabe M, Aonuma K, Hirayama A, Tamaki N, Tsutsui $\mathrm{H}$, et al. Proteinuria and reduced estimated glomerular filtration rate are independent risk factors for contrast-induced nephropathy after cardiac catheterization. Circ J. 2015;79(7):1624-30.

37 Pérez-Topete SE, Miranda-Aquino T, GascaLuna K, Guerra-Villa MN, Elizondo-Adamchik HE. Contrast-induced nephropathy in patients undergoing percutaneous coronary intervention. Rev Mex Cardiol. 2016;27(2): 64-70.

38 Lele SS, Mukhopadhyay BN, Mardikar MM, Patel TA, Vasavada AK, Banker DN, et al. Impact of catalytic iron on mortality in patients with acute coronary syndrome exposed to iodinated radiocontrast-The Iscom study. Am Heart J. 2013;165(5):744-51.

39 Takahashi EA, Kallmes DF, Fleming CJ, McDonald RJ, McKusick MA, Bjarnason $\mathrm{H}$, et al. Predictors and outcomes of postcontrast acute kidney injury after endovascular renal artery intervention. J Vasc Interv Radiol. 2017;28(12):1687-92.

40 Kanic V, Kompara G, Šuran D, Tapajner A, Naji FH, Sinkovic A. Acute kidney injury in patients with myocardial infarction undergoing percutaneous coronary intervention using radial versus femoral access. BMC Nephrol. 2019;20(1):28. 
41 Velibey Y, Oz A, Tanik O, Guvenc TS, Kalenderoglu K, Gumusdag A, et al. Platelet-tolymphocyte ratio predicts contrast-induced acute kidney injury in patients with ST-segment elevation myocardial infarction undergoing primary percutaneous coronary intervention. Angiology. 2017;68(5):419-27.

$42 \mathrm{Hu} \mathrm{Y,} \mathrm{Li} \mathrm{Z,} \mathrm{Chen} \mathrm{J,} \mathrm{Shen} \mathrm{C,} \mathrm{Song} \mathrm{Y,} \mathrm{Zhong} \mathrm{Q.}$ Risk factors for acute kidney injury in patients undergoing same admission coronary angiography and valve replacement. J Card Surg. 2013;28(6):627-31.

43 Chen H, Yu X, Ma L. Risk factors of contrastinduced nephropathy in patients with STEMI and pump failure undergoing percutaneous coronary intervention. Exp Ther Med. 2021; 21(2): 140 .

44 Qin Y, Tang H, Yan G, Wang D, Qiao Y, Luo $\mathrm{E}$, et al. A high triglyceride-glucose index is associated with contrast-induced acute kidney injury in Chinese patients with type 2 diabetes mellitus. Front Endocrinol. 2020;11: 522883.

45 Prasad A, Rosenthal NA, Kartashov A, Knish K, Dreyfus J. Contemporary trend of acute kidney injury incidence and incremental costs among US patients undergoing percutaneous coronary procedures. Catheter Cardiovasc Interv. 2020;96(6):1184-97.

46 Zuo P, Li Y, Zuo Z, Wang X, Ma G. Glycemic variability as predictor of contrast-induced nephropathy in diabetic patients with acute myocardial infarction undergoing percutaneous coronary intervention. Ann Transl Med. 2020;8(22):1505.

47 Wang C, Li G, Liang X, Qin C, Luo Q, Song R, et al. Predictive value of fibrinogen-to-albumin ratio for post-contrast acute kidney injury in patients undergoing elective percutaneous coronary intervention. Med Sci Monit. 2020;26:e924498.

48 Yoo J, Hong JH, Lee SJ, Kim YW, Hong JM, $\mathrm{Kim} \mathrm{CH}$, et al. Acute kidney injury after endovascular treatment in patients with acute ischemic stroke. J Clin Med. 2020;9(5):1471.
49 Zorlu C, Koseoglu C. Comparison of the relationship between inflammatory markers and contrast-induced nephropathy in patients with acute coronary syndrome after coronary angiography. Angiology. 2020;71(3):249-55.

50 Wang Y, Shi Y, Xu X, Ge W, Yang S, Lu C. Effects of probucol on contrast-induced acute kidney injury in patients undergoing percutaneous coronary intervention. Medicine. 2019; 98(25):e16049.

51 Tanik VO, et al. Neutrophil-to-lymphocyte ratio predicts contrast-induced acute kidney injury in patients with ST-elevation myocardial infarction treated with primary percutaneous coronary intervention. J Tehran Heart Cent. 2019;14(2):59-66.

52 Chalikias G, Drosos I, Tziakas DN. Contrastinduced acute kidney injury: an update. Cardiovasc Drugs Ther. 2016;30(2):215-28.

53 Yi Q, Li K, Jian Z, Xiao YB, Chen L, Zhang Y, et al. Risk factors for acute kidney injury after cardiovascular surgery: evidence from 2,157 cases and 49,777 controls: a meta-analysis. Cardiorenal Med. 2016;6(3):237-50.

54 Briguori C, Quintavalle C, De Micco F, Condorelli G. Nephrotoxicity of contrast media and protective effects of acetylcysteine. Arch Toxicol. 2011;85(3):165-73.

55 Keaney JJ, Hannon CM, Murray PT. Contrast-induced acute kidney injury: how much contrast is safe? Nephrol Dial Transpl. 2013; 28(6):1376-83.

56 Romano G, Briguori C, Quintavalle C, Zanca C, Rivera NV, Colombo A, et al. Contrast agents and renal cell apoptosis. Eur Heart J. 2008;29(20):2569-76.

57 Nguyen LS, Spagnoli V, Kerneis M, HauguelMoreau M, Barthélémy O, Collet JP, et al. Evaluation of neutrophil gelatinase-associated lipocalin and cystatin $\mathrm{C}$ as biomarkers of acute kidney injury after ST-segment elevation myocardial infarction treated by percutaneous coronary intervention. Arch Cardiovasc Dis. 2019;112(3):180-6.
58 Lee J, Cho JY, Lee HJ, Jeong YY, Kim CK, Park BK, et al. Contrast-induced nephropathy in patients undergoing intravenous contrast-enhanced computed tomography in Korea: a multi-institutional study in 101487 patients. Korean J Radiol. 2014;15(4):456-63.

59 Neyra JA, Shah S, Mooney R, Jacobsen G, Yee J, Novak JE. Contrast-induced acute kidney injury following coronary angiography: a cohort study of hospitalized patients with or without chronic kidney disease. Nephrol Dial Transpl. 2013;28(6):1463-71.

60 Liu J, Sun G, He Y, Song F, Chen S, Guo Z, et al. Early $\beta$-blockers administration might be associated with a reduced risk of contrast-induced acute kidney injury in patients with acute myocardial infarction. J Thorac Dis. 2019;11(4):1589-96.

61 Shiba A, Uchino S, Fujii T, Takinami M, Uezono S. Association between intraoperative oliguria and acute kidney injury after major noncardiac surgery. Anesth Analg. 2018; 127(5):1229-35.

62 Liu Y, Liu Y, Li H, Zhou Y, Guo W, Duan C, et al. Percutaneous coronary intervention for chronic total occlusion improved prognosis in patients with renal insufficiency at high risk of contrast-induced nephropathy. Sci Rep. 2016;6:21426.

63 Okumura N, Hayashi M, Ishii H, Yoshikawa D, Yasuda Y, Goto M, et al. Novel preprocedural and acute-phase postprocedural predictive factors for contrast-induced kidney injury in CKD patients. Int J Cardiol. 2014;172(2): e293-6.

64 Izkhakov E, Rozenbaum Z, Margolis G, Khoury S, Keren G, Shacham Y. Prolonged hyperglycemia and renal failure after primary percutaneous coronary intervention. Cardiorenal Med. 2019;9(2):92-9.

65 Butt K, D’Souza J, Yuan C, Jayakumaran J, Nguyen M, Butt HI, et al. Correlation of the neutrophil-to-lymphocyte ratio (NLR) and platelet-to-lymphocyte ratio (PLR) with contrast-induced nephropathy in patients with acute coronary syndrome undergoing percutaneous coronary interventions. Cureus. 2020;12(12):e11879. 